\title{
Impact of Husbands' Participation in Antenatal Health Education Services on Maternal Health Knowledge
}

\author{
Mullany BC, ${ }^{1}$ Lakhey $B,{ }^{2}$ Shrestha $D,{ }^{3}$ Hindin $M J,{ }^{1}$ Becker $S^{1}$ \\ 'Johns Hopkins Bloomberg School of Public Health, Department of International Health, 621 North Washington Street, \\ Baltimore, USA, ${ }^{2}$ Service Delivery Project, Nepal Fertility Care Center, Kathmandu, Nepal, ${ }^{3}$ Local Study Coordinator, Male \\ Involvement in Antenatal Care Study, Prashuti Griha Maternity Hospital, Kathmandu, Nepal
}

\section{ABSTRACT}

Introduction: A randomized controlled trial was designed to test the impact of involving husbands in antenatal health education on women's maternal health knowledge.

Methods: Total 442 women receiving antenatal services at a hospital in Kathmandu, Nepal were randomized into three groups: women who attended education sessions with their husbands, women who attended education sessions alone, and women who attended no education sessions (controls). At baseline and after delivery, women's maternal health knowledge and change in knowledge levels were compared between the groups.

Results: Compared to control group women, women educated with husbands increased their knowledge scores by an average of 0.61 points $(95 \% \mathrm{CI}=0.32-0.89, \mathrm{P}<0.001)$, while women educated alone increased their scores by only 0.34 points $(95 \% \mathrm{CI}=0.04-0.65, \mathrm{P}<0.05)$. Women educated with partners could identify more pregnancy complications and family planning methods than women in both other groups.

Conclusions: These findings suggest that women learn and retain the most information when they are educated with their partners.

Keywords: couples intervention; male involvement; maternal health; Nepal

\section{INTRODUCTION}

Men possess little knowledge regarding reproductive health (particularly pregnancy health) but much decision-making power in South Asia. ${ }^{1-7}$ Given this dynamic, traditional avenues for administering maternal and child health education - only to women - may have limited effectiveness. Educating male partners may increase women's health knowledge and behaviors by promoting interaction and communication between the couple, as suggested by social cognitive and social network theories. ${ }^{8-10}$

While findings in the areas of family planning and STIs indicate the potential success of 'couple-friendly' reproductive health services, the influence of men during pregnancy remains unexplored. ${ }^{11-14}$ Recent studies in Turkey and India found that women educated with

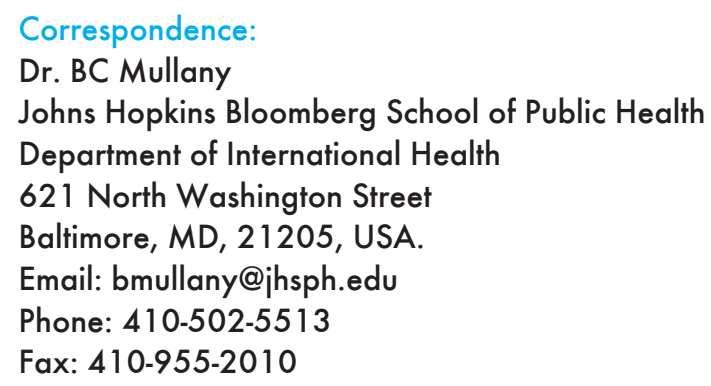

Fax: 410-955-2010 
Mullany et al. Impact of husbands' participation in antenatal health education services on maternal health knowledge

husbands experienced increased modern contraceptive use and reproductive health knowledge levels, but these interventions' combinations of group and couples components made it difficult to discern which approach was most effective. ${ }^{15,16}$

\section{METHODS}

Using a randomized controlled trial design, the impact of providing antenatal health education to pregnant women and their husbands in a couples format, compared to educating women alone or not providing education, was evaluated on women's maternal and reproductive health practices and knowledge levels in Kathmandu, Nepal from August, 2003 - January, 2004. Findings related to maternal health practices are reported elsewhere. ${ }^{17}$

With a total catchment area estimated at 1.1 million people, Prashuti Griha Maternity Hospital, Kathmandu (PGMH) has approximately 250 beds and has roughly 16,000 deliveries each year. ${ }^{25}$ Approximately $40 \%$ of ANC clinic patients at PGMH are accompanied by their husbands, who normally wait on the hospital grounds during the time of their wives' visits. ${ }^{26}$

All study procedures were approved by the Johns Hopkins Committee on Human Research (Baltimore, MD), the Nepal Health Research Council (Kathmandu, Nepal) and the Prashuti Griha Maternity Hospital Ethical Approval Committee.

Briefly, women who received education with their husbands were significantly more likely to utilize postpartum care than women who were educated alone or women who did not receive the education intervention. Higher levels of birth preparedness were seen among women who received education in either format (couples or alone), as compared to women who did not receive any education. ${ }^{17}$ In order to better understand the impact of including male partners in pregnancy health services, this paper presents findings related to the secondary outcomes of changes in knowledge levels associated with the couples antenatal health education intervention.

Married women attending their first ANC visit at PGMH (gestational age 16-28 weeks) whose husbands were present at the hospital compound were eligible to participate in the trial. Systematic random sampling techniques were used to approach eligible women for recruitment. Using the statistical software program Stata 8.0 (Stata Corp., College Station, TX), a list was generated randomizing the sequence of recruitment of study groups for each day of the recruitment period. Upon administration of written, informed consent procedures, 442 participants were randomly assigned to one of three study arms (Figure 1):

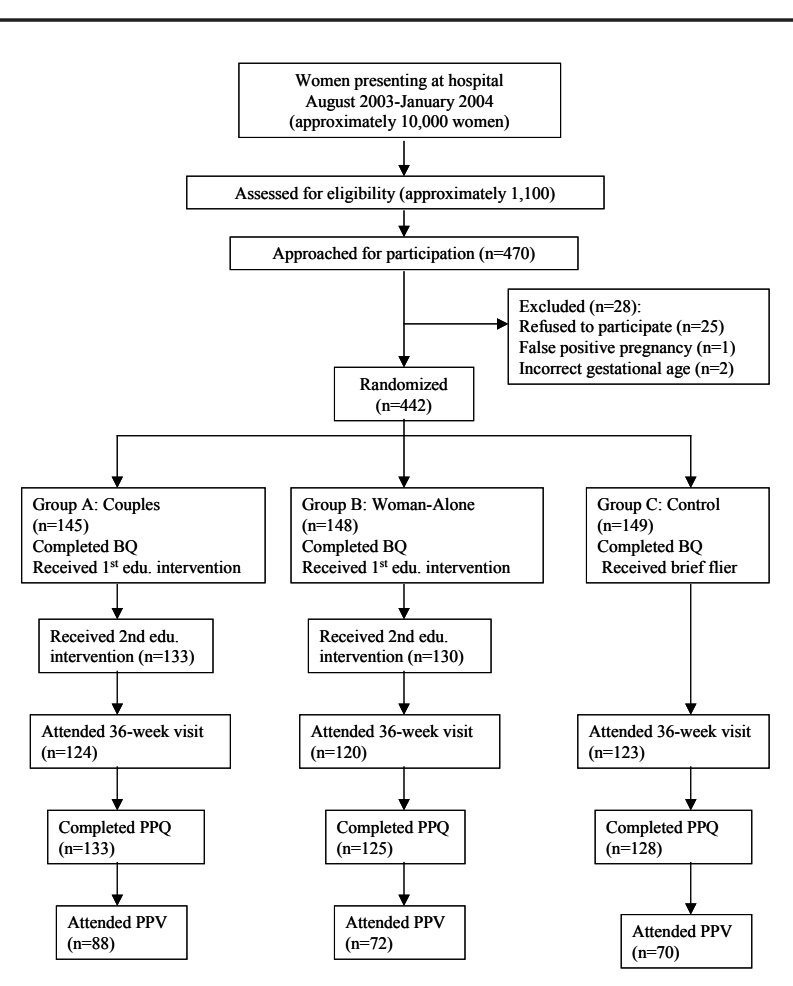

Figure 1. CONSORT diagram of study participants and their study participation (BO = baseline questionnaire, $\mathrm{PPQ}=$ postpartum questionnaire, $\mathrm{PPV}=$ postpartum checkup visit).

Group A - husband and wife received health education together

Group B - wife received health education alone

Group C - wife received no education (control)

Upon enrollment, a baseline questionnaire was administered that collected information on women's socio-demographic background, reproductive history, and maternal health knowledge and practices. All women were requested to attend the hospital for a final ANC checkup at approximately 36 weeks gestational age. Additionally, all women were encouraged to deliver in the hospital and to attend a postpartum checkup within two weeks of delivery at PGMH. To minimize loss to follow-up, postpartum questionnaires that collected information on maternal health knowledge and practices were completed either immediately prior to discharge or at the postpartum checkup. For those not returning within two weeks of delivery, home visits were conducted during which research assistants administered the postpartum questionnaires.

The health education intervention consisted of two 35 -minute sessions delivered in a private room in the hospital with pregnant women and their husbands when applicable. Participants in the intervention groups received the first health education session on the day 
Mullany et al. Impact of husbands' participation in antenatal health education services on maternal health knowledge

of enrollment and were asked to return to $\mathrm{PGMH}$ for the second health education session approximately 4-6 weeks later.

The intervention was based on principles from the theory of reasoned action and the health belief model, and covered a number of maternal health topics, including nutrition during pregnancy, breastfeeding, pregnancy complications and family planning. ${ }^{18,19}$ Female study nurses and male auxiliary health workers provided health information on each of the topics into talking points supplemented with culturally adapted, easy-to-follow graphic materials. The couples study arm consisted of one couple receiving a face-to-face education session administered jointly by one male health worker and one female nurse. Women educated alone received an individual face-to-face education session with a female worker. All health educators received a standardized training course and followed structured intervention protocols. Both intervention groups received the same curriculum messages.

Approximately $15 \%$ of Nepal's 27.5 million people live in urban areas; the largest of these is the capital city of Kathmandu (20). While ANC coverage is relatively adequate ( $82 \%$ of women attend at least 1 visit), other maternal health indicators are in need of improvement. High rates of anemia and home delivery (30-40\%), in addition to inadequate weight gain and low postnatal care utilization (approximately 12\%), contribute to lingering poor maternal and infant health outcomes in urban Nepal. ${ }^{21-24}$

Women were excluded if they were $<18$ years of age or lived $>90$ minutes away from PGMH (due to logistical constraints in tracking down participants).

Maternal and reproductive health knowledge levels were assessed through a series of seven questions (Table 1). Responses were coded and assigned: 1 point if completely correct, 0.5 points if partially correct (in questions 1, 3 and 6 ), and 0 points if either 'don't know' or an incorrect answer was given. Baseline and followup knowledge scores were created ranging from 0-7 points. A 'change in knowledge' variable was created based on the difference between each woman's baseline and follow-up knowledge score. Follow-up knowledge scores were also dichotomized into either 'high/low' or 'improve/did not improve.'

Study participants were coded as lost to follow-up if no postpartum questionnaire was completed. Baseline variables were compared between groups using the student's t (continuous) and chi-squared (binary) tests. Similarly, differences between participants versus nonparticipants, as well as between those who completed the study versus those who did not, were examined. Univariate and multivariate linear regression analyses were conducted using the follow-up knowledge score and change in knowledge variables as continuous outcomes. Crude and adjusted relative risks with $95 \%$ confidence intervals were calculated for dichotomized study outcomes. Analyses were conducted with Stata 8.0 and followed an intent-to-treat approach.

\section{RESULTS}

Consort diagram of study participants and their study participation were used in this study (Figure 1). Attrition rates for each of the study points of contact were generally low and the levels of missing data for any one variable were negligible $(<1 \%)$. Adherence to the intervention education sessions was high, with $92 \%$ and $88 \%$ of women from the couples and woman-alone groups, respectively, returning for the second education session. Between $77-86 \%$ of women in each study group returned for the 36 -week visit, and follow-up rates for the postpartum questionnaire were also high $192 \%$ for couples group, $85 \%$ for woman-alone group, and $86 \%$ for the control group. All analysis including the follow-up knowledge outcomes was limited to the women who completed postpartum questionnaires $(n=386)$.

Characteristics of the study population at baseline ( $n=442$ ) were compared, and no statistically significant differences $(P<0.05)$ between the three groups were found, suggesting successful randomization (17). Although educational status and caste were not significantly different at the $\mathrm{P}=0.05$ level between study groups at baseline, these variables, as well as any other potential confounders, were included in all subsequent adjusted models in order to account for minor imbalances.

Unadjusted summary knowledge measures indicate significant differences between the groups in the follow-up knowledge scores as well as in the change in knowledge variable (Table 1). In addition, a general pattern of increased knowledge from baseline to followup is seen among all three groups, with the largest increase usually being seen among women in the couples group.

When entered into multivariate linear regression models, the majority of the differences among groups remained significant (Table 2). Adjusting for their educational status and knowledge level at baseline and other potential confounders, women educated with husbands experienced an average of $0.61[95 \% \mathrm{Cl}=(0.32-0.89)$, $\mathrm{P}<0.001]$ and $0.26[95 \% \mathrm{Cl}=(-0.05-0.57), \mathrm{P}<0.1]$ points greater increase in knowledge from baseline to follow-up compared to women in the control or womanalone groups, respectively. In comparison, women who received education alone experienced an average of 
Mullany et al. Impact of husbands' participation in antenatal health education services on maternal health knowledge

$0.34[95 \% \mathrm{Cl}=(0.04-0.65), \mathrm{P}<0.05]$ points increase in knowledge as compared to control-group women.

The unadjusted and adjusted relative risks of various dichotomous knowledge outcomes (Table 3). After adjustment for covariates, findings suggest that women in the couples group had more knowledge of pregnancy complications at the time of follow-up compared to woman-alone group women $(\mathrm{RR}=1.15,95 \% \mathrm{Cl}=1.00$ 1.32) and control group women $(R R=1.13,95 \%$ $\mathrm{Cl}=0.99-1.31)$. Similarly, couples group women had higher family planning knowledge compared to women educated alone $(R R=1.09,95 \% \mathrm{Cl}=1.02-1.18)$ and control group women $(R R=1.07,95 \% \mathrm{Cl}=1.00-1.14)$. There were no differences between the woman-alone group and the control group.

Upon dichotomizing the follow-up knowledge scores into either 'high/low' or 'improve/did not improve,' similar patterns were seen with respect to study group before and after adjustment for covariates (Table 3 ). Women educated with their husbands were slightly more likely to have high knowledge scores at followup as compared to control group women $(R R=1.14$, $95 \% \mathrm{Cl}=0.99,1.31)$ and to women educated alone ( $R R=1.18,95 \% \mathrm{Cl}=1.01,1.38)$. In contrast, women in the woman-alone group showed no significant increases in having 'high' follow-up knowledge compared to the control group. Only the women educated with partners were significantly more likely to show improvement in knowledge from baseline to follow-up as compared to control group women $(R R=1.25,95 \% \mathrm{Cl}=1.04,1.51)$ both before and after adjustment.

\section{DISCUSSION}

Based on a randomized trial design, a generally consistent pattern was found in which women who received education with their husbands experienced the greatest gains in knowledge, followed by women who received education alone, and with the lowest knowledge levels seen among control group women. Although individual results were only marginally significant, women in the couples group had significantly higher knowledge as compared to control group women in all summary knowledge measures. In contrast, women educated alone had higher knowledge compared to control group women only in a few domains, and when they did so, the magnitude of the difference was less than that seen for couples group women. Despite apparent slight imbalances in background factors such as caste and educational status at baseline, the comparison of adjusted to unadjusted results indicates that improvements in knowledge levels were likely to have occurred as a result of the intervention.

Increased communication and interaction between spouses regarding health practices during or after the education sessions may have led to a greater understanding and/or retention of new information. Although the premise for these findings is supported by several health education and behavior change theories, future in-depth qualitative research should examine what underlying mechanisms or motivations may be influencing the different learning (or retention) patterns seen in this study. Additionally, further intervention research is needed to replicate these findings in other settings. Involving sources of support from women's social networks other than male partners also merits further examination. The enhanced knowledge attainment seen in women receiving education with their husbands in this trial might, for instance, also be seen if another individual (who provides instrumental and emotional support to the woman) is present (e.g., mother-in-law, sister). In this setting however, designing a trial which included husbands was a logical choice since men tend to dominate decision-making and over $40 \%$ of pregnant women are accompanied by their husbands to ANC (compared to roughly $9 \%$ by motherin-law and $<5 \%$ by friends/other relatives) (26).

This study had several limitations. The intervention targeted poor urban women seeking antenatal services, an important and growing population in Nepal. While women at PGMH are likely to be poorer than those seeking services at private hospitals or antenatal clinics in Kathmandu, they are also likely to be wealthier, better educated, and/or more motivated than women receiving no ANC. Even though health services for destitute individuals are free at $\mathrm{PGMH}$, and only a small fee is charged for other patients, seeking ANC already makes these women 'special,' in the sense that they (or someone in their lives) had the motivation to take this preventive health measure. Since over $80 \%$ of urban Nepalese women receive at least one ANC visit, and the site of this study represents the primary ANC service provider for the population of Kathmandu Valley, the potential selection biases are likely limited (24).

In order to avoid resource-intensive home visits to recruit husbands not present at PGMH (reaching men in their homes would require a different strategy), women were only eligible for this study if their husbands were present at the hospital. Previous research at PGMH has shown that women accompanied by husbands to ANC are similar with respect to most background characteristics to women unaccompanied by husbands, with the exception of parity. Women with children are about half as likely to have their husbands accompany them to ANC as women without children. The formative qualitative research that preceded this study, however, suggested that most men who were not present were unable to attend ANC due to their job constraints, rather than childcare responsibilities. Women who were accompanied by their husbands to ANC were also slightly more likely to report sharing problems with their husbands, implying a level of emotional support that may be different from women who were 
Mullany et al. Impact of husbands' participation in antenatal health education services on maternal health knowledge

Table 1. Percentage distribution of unadjusted knowledge outcomes and comparison between randomized groups at baseline and at follow-up $(n=386)$.

\begin{tabular}{|c|c|c|c|c|c|c|}
\hline & \multicolumn{3}{|c|}{ Study Group, Baseline } & \multicolumn{3}{|c|}{ Study Group, Follow-up } \\
\hline & $\begin{array}{l}\text { Couples } \\
(n=133)\end{array}$ & $\begin{array}{l}\text { Woman- } \\
\text { Alone } \\
(n=125)\end{array}$ & $\begin{array}{l}\text { Control } \\
(n=128)\end{array}$ & $\begin{array}{l}\text { Couples } \\
(n=133)\end{array}$ & $\begin{array}{l}\text { Woman- } \\
\text { Alone } \\
(n=125)\end{array}$ & $\begin{array}{l}\text { Control } \\
(n=128)\end{array}$ \\
\hline \multicolumn{7}{|l|}{ Summary Knowledge Outcomes } \\
\hline $\begin{array}{l}\text { Knowledge score (range 0-7) } \\
\text { (Mean, SD) }\end{array}$ & $3.7(1.5)$ & $3.4(1.5)$ & $3.6(1.5)$ & $4.7(1.4)^{* \dagger}$ & $4.2(1.6)$ & $4.0(1.4)$ \\
\hline $\begin{array}{l}\text { Has 'high' (>median) knowledge } \\
\text { score }(\%)\end{array}$ & 48.9 & 42.4 & 51.6 & $75.9 *+$ & 59.2 & 64.1 \\
\hline $\begin{array}{l}\text { Change in knowledge score } \\
\text { (Mean, SD) }\end{array}$ & & & & $0.99(1.5)^{*}$ & $0.82(1.4)^{\ddagger}$ & $0.40(1.4)$ \\
\hline $\begin{array}{l}\text { Improved knowledge, baseline- } \\
\text { follow-up (\%) }\end{array}$ & & & & $67.7 *$ & 61.6 & 54.7 \\
\hline
\end{tabular}

${ }^{*} \mathrm{P}<0.05$ for Couples vs. Control; ${ }^{\dagger} \mathrm{P}<0.05$ for Couples vs. Woman-Alone; ${ }^{\ddagger} \mathrm{P}<0.05$ for Woman-Alone vs. Control

\section{Individual Knowledge Questions}

1. Timing of pregnancy risk: From the beginning of one menstrual period to the next, is there a time when a woman is more likely to become pregnant if she has sexual relations? [If yes]: When would you say this time is?

2. Pregnancy complications: Even though most pregnancies are normal, some women do experience complications that can lead to sickness \& even death. What are signs that show a pregnant woman is having serious problems \& should be taken to health facility?

3. Condoms: What are condoms used for?

4. Sexually transmitted infections: If a person has a STI but does not physically show any signs, can he or she still pass the infection on to his/her partner?

5. Family planning: Which family planning methods have you heard of?

6. Weight gain during pregnancy: After becoming pregnant and before delivery, approximately how much weight (in kgs) should women gain?

7. Breastfeeding: How soon after delivery is the best time to start breastfeeding?

unaccompanied by their husbands (26). Despite the potential limitations on the generalizability of these findings, it is important to bear in mind that this study population was representative of almost half of women who seek antenatal care services at the predominant maternal health facility in Kathmandu Valley (5).

Though not formally recorded in the current study, the additional resources required for including men in the health education sessions in this setting were relatively minimal. Only two male health educators were hired in addition to the female health educators, and the duration of the health education sessions administered to couples was the same as for sessions administered to women alone. Future studies should consider costeffectiveness analyses to assess to what extent the knowledge gain seen in women educated with husbands is worth the additional resources required as compared to educating women alone. In addition, Helzner has highlighted some of the potential risks of involving men in women's reproductive health services, particularly in terms of reinforcing patterns of male domination over decision-making (27). Although no negative effects of including men in antenatal care services were recorded in this study, caution must be exercised when exploring male involvement approaches in new settings.

While the 'couples' intervention design in this study required a relatively resource-intensive delivery format for health education messages, future interventions should explore other avenues for reaching wider audiences of males. Policy-makers and health care providers have traditionally implemented policies and procedures that are not conducive to males being included. Maternal health care services, for instance, are usually offered during hours when men are working, men are generally not allowed into checkup or delivery rooms of most hospitals and clinics, and providers often have a bias towards involving men in reproductive health services (28). In the setting for this study, although men regularly accompany their wives to the hospital, they are excluded from services. Such obstacles may be overcome through different approaches to health education. At this location, for example, general announcements could be made advertising health education sessions in the hospital 
Mullany et al. Impact of husbands' participation in antenatal health education services on maternal health knowledge

Table 2. Unadjusted and adjusted coefficients and $95 \%$ confidence intervals from linear regression models of women's knowledge scores $(n=386)$.

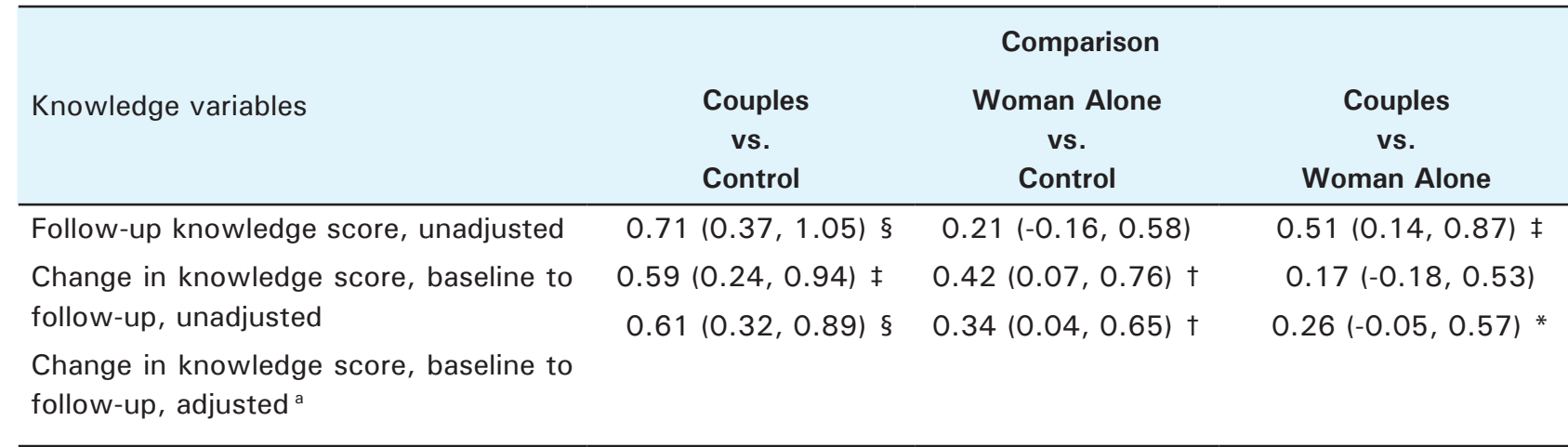

* $p<0.1 ; \dagger p<0.05 ; \ddagger p<0.01 ; \S p<0.001$

${ }^{a}$ Model adjusted for: woman's age, parity, educational status, baseline knowledge score, co-residence with motherin-law.

Table 3. Relative risk estimates and $95 \%$ confidence intervals for maternal health knowledge outcomes, by study group and comparison $(n=386)$.

\begin{tabular}{|c|c|c|c|}
\hline \multirow[b]{2}{*}{ Follow-up knowledge outcomes } & \multicolumn{3}{|c|}{ Comparison } \\
\hline & $\begin{array}{c}\text { Couples } \\
\text { vs. } \\
\text { Control }\end{array}$ & $\begin{array}{c}\text { Woman Alone } \\
\text { vs. } \\
\text { Control }\end{array}$ & $\begin{array}{c}\text { Couples } \\
\text { vs. } \\
\text { Woman Alone }\end{array}$ \\
\hline \multirow{2}{*}{$\begin{array}{l}\text { Knows at least one pregnancy complication, } \\
\text { unadjusted }\end{array}$} & \multicolumn{3}{|c|}{ Relative Risk (95\% confidence interval) } \\
\hline & $1.16(1.00,1.33)$ & $0.98(0.83,1.16)$ & $1.18(1.02,1.37)$ \\
\hline $\begin{array}{l}\text { Knows at least one pregnancy complication, } \\
\text { adjusted }^{\text {a }}\end{array}$ & $1.13(0.99,1.31)$ & $0.99(0.84,1.17)$ & $1.15(1.00,1.32)$ \\
\hline $\begin{array}{l}\text { Knows at least one family planning method, } \\
\text { unadjusted }\end{array}$ & $1.08(1.01,1.16)$ & $0.97(0.88,1.06)$ & $1.11(1.03,1.20)$ \\
\hline $\begin{array}{l}\text { Knows at least one family planning method, } \\
\text { adjusted }^{\text {a }}\end{array}$ & $1.07(1.00,1.14)$ & $0.98(0.89,1.07)$ & $1.09(1.02,1.18)$ \\
\hline High ( > median) knowledge score, unadjusted & $1.19(1.01,1.39)$ & $0.92(0.76,1.12)$ & $1.28(1.08,1.53)$ \\
\hline High (> median) knowledge score, adjusted ${ }^{a}$ & $1.14(0.99,1.31)$ & $0.99(0.83,1.17)$ & $1.18(1.01,1.38)$ \\
\hline $\begin{array}{l}\text { Improved knowledge from baseline to follow- } \\
\text { up, unadjusted }\end{array}$ & $1.24(1.02,1.51)$ & $1.13(0.91,1.39)$ & $1.09(0.92,1.32)$ \\
\hline $\begin{array}{l}\text { Improved knowledge from baseline to follow- } \\
\text { up, adjusted }\end{array}$ & $1.25(1.04,1.51)$ & $1.09(0.89,1.33)$ & $1.14(0.96,1.35)$ \\
\hline
\end{tabular}

a Models adjusted for: woman's age, parity, educational status, baseline knowledge score, co-residence with mother-in-law.

compound/parking area (where husbands wait during their wives' ANC appointments) and husbands could then be gathered into a large room for group education sessions. In addition, the use of different educational media should be explored, including the provision of fliers and the projection of educational videos on large screens.

\section{CONCLUSION}

Though much research is still needed to examine the most effective ways of translating health knowledge into healthy behaviors, a fundamental first step to effective health promotion and behavior change is the acquisition of knowledge (29). The findings from this study show that educating women in conjunction with their partners may yield a greater impact on the attainment of maternal health knowledge than educating women alone or not educating women at all. Combined with results reported elsewhere on the improved maternal health behaviors seen in women who received education with their husbands compared to women who received education alone (17), the findings in this paper suggest that women may learn and retain more information when they are educated with their partners rather than being educated alone. 
Mullany et al. Impact of husbands' participation in antenatal health education services on maternal health knowledge

\section{ACKNOWLEDGEMENTS}

This project was made possible through a Hopkins Population Center Dissertation Fieldwork Grant, awarded by the Andrew Mellon Foundation, and a grant awarded by the Bill \& Melinda Gates Institute for Population \&
Reproductive Health. We also wish to thank Dr. Kasturi Malla for her collaboration and valuable insight during the conduct of this study, as well as the local research team members and study participants in Kathmandu, Nepal.

\section{REFERENCES}

1. Beegle K, Frankenberg E, Thomas D. Bargaining power within couples and use of prenatal and delivery care in Indonesia. Stud Fam Plann 2001; 32(2):130-146.

2. Bloom SS, Wypij D, Das GM. Dimensions of women's autonomy and the influence on maternal health care utilization in a north Indian city. Demography 2001; 38(1):6778

3. Dudgeon MR, Inhorn MC. Men's influences on women's reproductive health: medical anthropological perspectives. Soc Sci Med 2004; 59(7):1379-1395.

4. Matsuyama A. Effects of education on health knowledge, perception, and behavior of women and their family during pregnancy, delivery, and postpartum period in Kathmandu Valley, Nepal. Ph.D. Dissertation, Johns Hopkins University. 2002.

5. Mullany BC, Hindin MJ, Becker S. Can women's autonomy impede male involvement in pregnancy health in Katmandu, Nepal? Soc Sci Med 2005; 61:1993-2006.

6. Piet-Pelon N, Rob U, Khan ME. Men in Bangladesh, India and Pakistan: reproductive health issues. New Delhi, India. 1999.

7. Thaddeus S, Maine D. Too far to walk: maternal mortality in context. Soc Sci Med 1994; 38(8):1091-1110.

8. Baranowski T, Perry CL, Parcel GS. How individuals, environments, and health behavior interact: social cognitive theory. In: Glanz K, Lewis FM, Rimer BK, editors. Health Behavior and Health Education. San Francisco. Jossey-Bass. 1997: 153-178.

9. Heaney CA, Israel BA. Social networks and social support. In: Glanz K, Lewis FM, Rimer BK, editors. Health Behavior and Health Education. San Francisco. Jossey-Bass. 1997: 179-205.

10. Loevinsohn BP. Health education interventions in developing countries: a methodological review of published articles. Int J Epidemiol 1990; 19(4):788-794.

11. Becker S. Couples and reproductive health: a review of the studies. Stud Fam Plann 1996; 27(6):291-306.

12. Danielson R, Barbey A, Cassidy D, Rosenzweig J, Chowdhury D. Couple-friendly services in a metropolitan sexually transmitted disease clinic: views of clients and providers. Fam Plann Perspect 1999; 31(4):195-199.

13. Sternberg P \& Hubley J. Evaluating men's involvement as a strategy in sexual and reproductive health promotion. Health Promot Int 2004, 19(3):389-396.

14. Becker $S$ \& Robinson JC. Reproductive health care: services oriented to couples. Int J Gynaecol Obstet 1998; 61(3): 275281.

15. Turan JM, Nalbant H, Bulut A, Sahip Y. Including expectant fathers in antenatal education programmes in Istanbul, Turkey. Reprod Health Matters 2001; 9(18):114-125.
16. Varkey LC, Mishra A, Das A, Ottolenghi E, Huntington D, Adamchak $\mathrm{S}$ et al. Involving men in maternity care in India. Washington DC, Population Council. Frontiers Final Report. 2004.

17. Mullany BC, Becker S, Hindin MJ. The impact of including husbands in antenatal health education services on maternal health practices in urban Nepal. Health Education Research 2007; 22(2): 166-176.

18. Ajzen I, Fishbein M. Understanding attitudes and predicting social behavior. Englewood Cliffs, New Jersey: Prentice-Hall, Inc. 1980.

19. Janz NK, Becker MH. The Health Belief Model: a decade later. Health Educ Q 1984; 11(1):1-47.

20. His Majesty's Government. Nepal Population Report 2002. Kathmandu, Nepal, Ministry of Population and Environment. 2002.

21. Bondevik GT, Ulstein M, Lie RT, Rana G, Kvale G. The prevalence of anemia in pregnant Nepali women--a study in Kathmandu. Acta Obstet Gynecol Scand 2000; 79(5):341-349.

22. MIRA/UNICEF. LBW prevention and associated factors in 4 regions of Nepal: a multi-hospital based study. Kathmandu, Nepal, UNICEF. 2000.

23. Bolam A, Manandhar DS, Shrestha P, Ellis M, Malla K, Costello AM. Factors affecting home delivery in the Kathmandu Valley, Nepal. Health Policy Plan 1998; 13(2):152-158.

24. Ministry of Health His Majesty's Government of Nepal, New Era KN, ORC Macro CM. Nepal Demographic and Health Survey 2001. Family Health Division. 2002.

25. Ellis M, Manandhar DS, Manandhar N, Wyatt J, Bolam AJ, Costello AM. Stillbirths and neonatal encephalopathy in Kathmandu, Nepal: an estimate of the contribution of birth asphyxia to perinatal mortality in a low-income urban population. Paediatr Perinat Epidemiol 2000; 14(1):39-52.

26. Beenhakker B. The impact of male involvement in antenatal care in Kathmandu, Nepal. Ph.D. Dissertation, Johns Hopkins University. 2005.

27. Helzner JF. Men's involvement in family planning. Reprod. Health Matters 1996, 4(7):146-154.

28. Khan ME. Involving men in safe motherhood. Journal of Family Welfare 1997; 43(2):18-30.

29. Glanz K, Lewis FM, Rimer BK. The scope of health promotion and health education. In: Glanz K, Lewis FM, Rimber BK, editors. Health Behavior and Health Education. San Francisco. Jossey-Bass. 1997: 3-18.

Note: Numbers may increase in the flow diagram because participants may have missed one visit and returned later. 